\title{
СРАВНИТЕЛЬНАЯ ФИЗИКО-ХИМИЧЕСКАЯ И ТЕХНОЛОГИЧЕСКАЯ ХАРАКТЕРИСТИКА ПРИРОДНЫХ ФОСФАТОВ
}

До недавнего времени в мировой химической промышленности находили применение всего несколько видов фосфатного сырья, главным образом апатитовый концентрат СССР, фосфоритные концентраты Северо-Африканских стран и США. В настоящее время и в ближайшем будущем в связи с большим ростом производства минеральных удобрений, изменениями в географии их производства и применения и быстрым исчерпыванием запасов некоторых старых месторождений в фосфатносырьевую базу привлекаются все новые виды фосфатов.

Как известно, фосфаты различных месторождений значительно отличаются по химико-минералогическому составу, физико-химическим свойствам, физической структуре, реакционной способности и т. д. Систематических исследований по изучению и сравнению состава и свойств фосфатов разных месторождений проведено сравнительно мало [']. Нами предпринята попытка создать комплексную сравнительную характеристику разных видов фосфатного сырья СССР, установить взаимосвязи между их составом и свойствами. Главное внимание уделено оболовым фосфоритам Эстонской ССР и Ленинградской области (месторождений Маарду, Кингисепп, Тоолсе и др.).

Важную часть комплексной характеристики фосфатного сырья составляет его химико-минералогический состав. Как известно, основным критерием фосфатного концентрата как сырья для химической переработки является содержание в нем $\mathrm{P}_{2} \mathrm{O}_{5}$ и примесей. При этом весовое соотношение $\mathrm{Fe}_{2} \mathrm{O}_{3}: \mathrm{P}_{2} \mathrm{O}_{5}$, не должно превышать $7-8 \%$, соотношение $\mathrm{MgO}: \mathrm{P}_{2} \mathrm{O}_{5}-6-8 \%$. Соотношение $\mathrm{CaO}: \mathrm{P}_{2} \mathrm{O}_{5}$, которое в основном определяет расход кислоты на единицу полезного вещества, должно быть возможно низким. Из фосфоритов СССР указанным требованиям отвечает маардуский фосфоритный концентрат (данные о химическом составе фосфатных концентратов СССР, а также марокканских и флоридских фосфоритов см. в таблице). В кингисеппском фосфорите, как и в фосфоритах Кара-Тау, зачастую содержание $\mathrm{MgO}$ превышает допустимые нормы, что затрудняет их кислотную переработку и ухудшает физико-химические свойства получаемых продуктов. Концентраты т. н. желваковых фосфоритов Русской платформы (Егорьевского, Вятского и др. месторождений) содержат значительное количество $\mathrm{Fe}_{2} \mathrm{O}_{3}$ и имеют высокое соотношение $\mathrm{CaO}: \mathrm{P}_{2} \mathrm{O}_{5}$, поэтому они малопригодны для процессов кислотной переработки. Необходимо подчеркнуть, что при оценке качества фосфоритов по содержанию $\mathrm{Fe}_{2} \mathrm{O}_{3}$ в них следует учитывать формы его. Например, в желваковых фосфоритах основная часть $\mathrm{Fe}_{2} \mathrm{O}_{3}$ представлена гидроксидами железа и глауконитом, которые хорошо 
растворяются в кислотах. Наоборот, в маардуских и тоолсеских фосфоритах железо связано в основном в виде пирита, который не растворяется в условиях получения суперфосфата и экстракционной фосфорной кислоты и не мешает процессам их получения. Однако это не относится к процессам азотнокислотного разложения, поскольку в данном случае пирит окисляется и вызывает восстановление части азотной кислоты в оксиды азота.

Окисляемость фосфатов, которая выражает содержание органического вещества, пирита, остатка флотореагентов и др. и определяется титрованием сернокислотной вытяжки фосфатов раствором перманганата калия, колеблется в значительных пределах. Она наиболее высока у фосфоритов маардуского и тоолсеского месторождений, поэтому они малопригодны для процессов азотнокислотного разложения. Однако в результате их обжига можно не только устранить этот недостаток, но и резко снизить растворимость железа. Таким образом, при оценке возможности использования природных фосфатов необходимо учитывать также особенности методов их обогащения и химической переработки.

Отдельные типы фосфатного сырья отличаются друг от друга не только видом и количеством примесей, но и составом самого фосфатного минерала. В настоящее время считают, что фосфатный минерал фосфоритов представлен фторкарбонатапатитом с бо́льшим или меньшим вхождением в структуру фторапатита карбонатиона.

Структура карбонатапатитов, согласно работам Борнеман-Старынкевича и Белова, основывается на замещении части фосфатиона фторапатита карбонатионом, причем вакансию одного атома кислорода занимает гидроксид- или фторидион.

$$
\begin{array}{cc}
\text { фторапатит } & \text { фторкарбонатапатит } \\
\mathrm{Ca}_{10}\left(\mathrm{PO}_{4}\right)_{6} \mathrm{~F}_{2} & \mathrm{Ca}_{10}\left(\mathrm{PO}_{4}\right)_{6-x}\left(\mathrm{CO}_{3}\right)_{x}(\mathrm{OH})_{y} \mathrm{~F}_{2+(x-y)} \\
\text { или } & \mathrm{Ca}_{10} \mathrm{P}_{6-x} \mathrm{C}_{x} \mathrm{O}_{24-x}(\mathrm{OH})_{y} \mathrm{~F}_{2+(x-y)}
\end{array}
$$

Перед нами стояла задача количественно определить содержание карбонатиона в фосфатном минерале различных природных фосфатов. Для отделения фосфатного минерала от кальцита, доломита и некоторых других примесей использовались методы избирательного растворения и частичного разложения фосфорита [2]. Результаты анализов, представленные в таблице, показывают, что по степени замещения фосфатиона карбонатионом основные фосфориты СССР могут быть разделены на 3 группы: каратауские, оболовые и желваковые. Химическая формула фосфатного вещества оболовых фосфоритов, например, оказалась следующей:

$$
\mathrm{Ca}_{9,4} X_{0,6} \mathrm{P}_{5,3} \mathrm{C}_{0,7} \mathrm{O}_{23,3}(\mathrm{OH})_{0,7} \mathrm{~F}_{2},
$$

где $X$ - катионы, замещающие кальций.

C замещением фосфатиона карбонатионом, по данным ИК-спектроскопии [3], нарушается симметрия анионов $\mathrm{PO}_{4}{ }^{3-}$ и $\mathrm{CO}_{3}{ }^{2-}$ (по сравнениюс фторапатитом и кальцитом), уменьшаются также плотность, показатель преломления и параметр а кристаллической решетки апатита. При прокаливании фосфоритов до $1000^{\circ} \mathrm{C}$ фторкарбонатапатит разлагается с выделением $\mathrm{CO}_{2}$ и переходит во фторапатит.

Для характеристики физической структуры фосфатных концентратов определялась их удельная поверхность - как общая, определенная по методу БЭТ с использованием низкотемпературной адсорбции азота, так и внешняя - по методу Товарова, основанному на измерении сопротивления, оказываемого слоем порошка проходящему воздуху. Установ- 


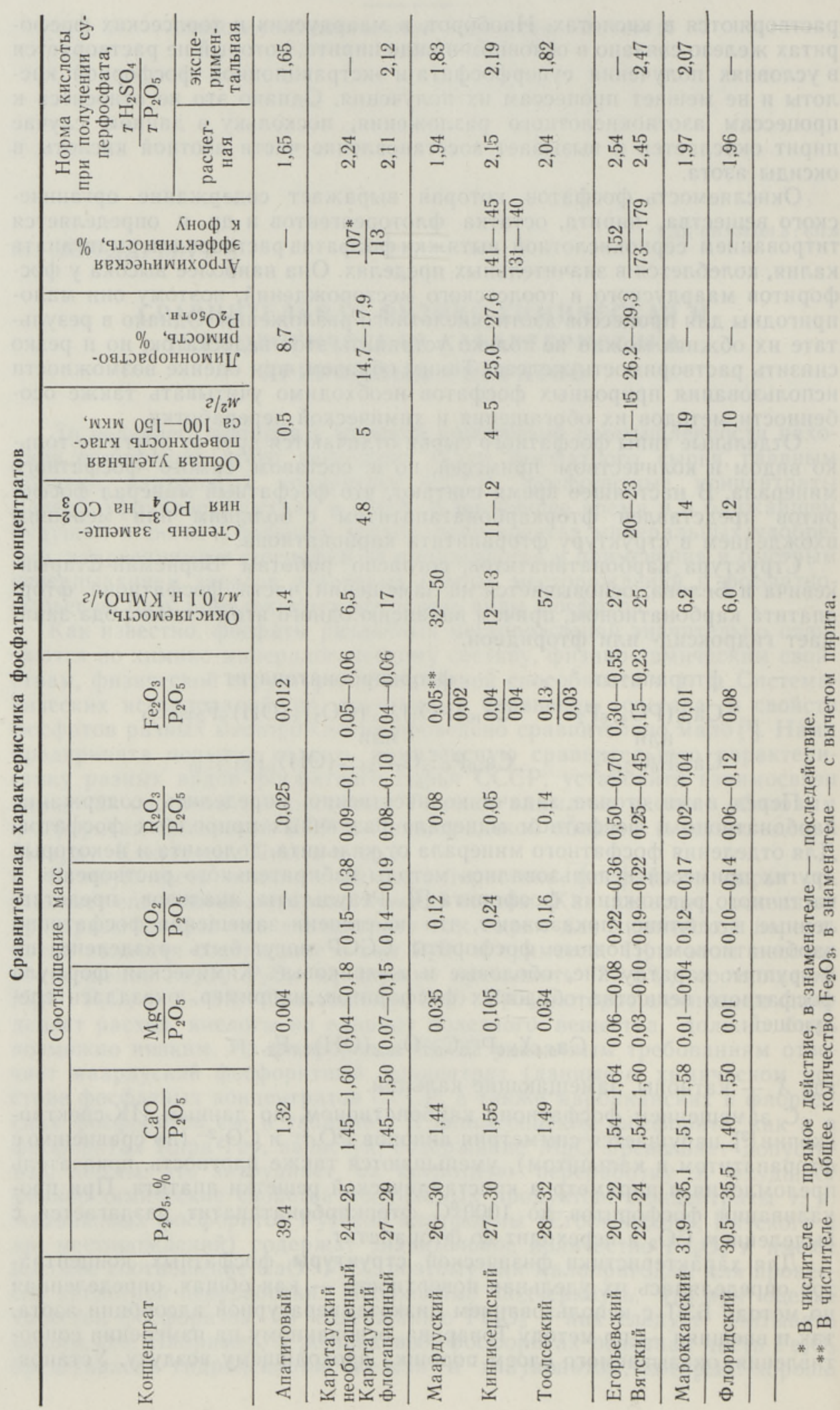


лено, что общая удельная поверхность фосфатов изменяется относительно немного при увеличении тонины их помола и является характерной величиной для каждого типа фосфата [4]. Из таблицы видно, что по этому показателю основные фосфатные концентраты СССР можно разделить на три группы: 1) апатитовые $\left.\left(<1,0 \mathrm{~m}^{2} / 2\right), 2\right)$ оболовые и каратауские $\left(4-5 \mathrm{M}^{2} / 2\right)$ и 3$)$ желваковые фосфориты $\left(>10 \mathrm{~m}^{2} / 2\right)$. Внешняя удельная поверхность различных фосфатов одинакового гранулометрического состава практически не различается и составляет небольшую часть от их общей поверхности, например, для класса $100-150$ мк у фосфоритов удельная поверхность составляет менее $1-2 \%$, у апатита примерно $10 \%$. Из полученных данных следует, что общая удельная поверхность фосфатов связана со степенью замещения фосфатиона карбонатионом в их фосфатном минерале. Чем больше в последнем карбонатиона, тем больше удельная поверхность (пористость) фосфата, и тем выше должна быть его реакционная способность.

При нагревании фосфоритов частицы становятся крупнее, общая удельная поверхность сокращается. Например, общая удельная поверхность нагретых до $1000^{\circ}$ проб оболовых фосфоритов составляет $0,5-1,5 \mathrm{M}^{2} / 2$, т. е. она приблизительно равна величине этого показателя у апатитового концентрата.

C практической точки зрения наибольший интерес представляет реакционная способность различных фосфатов. Хорошо известно, что различные виды фосфатного сырья разлагаются кислотами с различной скоростью, растворяются по-разному в растворах лимонной кислоты и других реагентов и показывают разный эффект при прямом внесении в почву. Однако необходимо учитывать, что различия в реакционной способности природных фосфатов не всегда значительны и иногда обусловлены влиянием примесей. Очень важно, чтобы для получения сравнительных данных в опытах с различными фосфатами норма и концентрация реагента, продолжительность и условия взаимодействия, тонина помола фосфата, температура и другие параметры были бы строго постоянными. Поэтому в наших исследованиях большое внимание было уделено методическим вопросам. Например, было найдено, что для более объективной характеристики лимоннорастворимости фосфатов количество раствора лимонной кислоты для обработки навески фосфата следует брать в зависимости от содержания $\mathrm{P}_{2} \mathrm{O}_{5}$ и примесей в последнем [5]. Данные о растворимости фосфатов в $2 \%$-ном растворе лимонной кислоты приведены в таблице, там же представлены средние результаты вегетационных и полевых опытов, проведенных по выяснению эффективности получения фосфоритной муки из этих фосфатов. Видно, что растворимость фосфатов в лимонной кислоте при указанной корректировке методики определения достаточно хорошо отражает их агрохимическую эффективность, а лимоннорастворимость и эффективность фосфатов тем выше, чем больше степень замещения фосфатиона карбонатионом в фосфатном минерале и чем больше общая удельная поверхность фосфата. При нагревании фосфоритов до температуры разложения фторкарбонатапатита их лимоннорастворимость резко уменьшается.

При оценке различных фосфатов с точки зрения кислотного разложения, наряду с содержанием в них $\mathrm{P}_{2} \mathrm{O}_{5}$ и примесей, немаловажное значение имеют норма кислоты, используемой для их обработки, и кинетика разложения. Данные по расчетному стехиометрическому и экспериментально определенному расходам кислоты при получении суперфосфата (в пересчете на 1 T $\mathrm{P}_{2} \mathrm{O}_{5}$ фосфата) приведены в таблице. За основу расчетной нормы приняты содержание в фосфате $\mathrm{P}_{2} \mathrm{O}_{5}, \mathrm{CaO}, \mathrm{MgO}, \mathrm{CO}_{2}$, $\mathrm{Fe}_{2} \mathrm{O}_{3}$. и $\mathrm{Al}_{2} \mathrm{O}_{3}$ и методика расчета, предложенная Чепелевецким и Бруц- 
кус. Выяснилось, что наименьший расход кислоты наблюдается при переработке маардуского и тоолсеского фосфоритов, при этом экспериментально определенный расход у них ниже расчетного. Это вызвано наличием в их составе пирита, который не разлагается серной кислотой, но учитывается при расчете стехиометрической нормы кислоты. Кинетические эксперименты с обработкой оболовых и желваковых фосфоритов растворами сильных кислот показали, что желваковые фосфориты (с большей степенью замещения фосфатиона карбонатионом) вначале разлагаются с несколько большей скоростью, чем оболовые, но на последующих стадиях уступают им по скорости и полноте разложения. Причиной последнего явления служат повышенное содержание полуторных оксидов в желваковых фосфоритах и вызванные ими вторичные реакции, которые приводят к снижению активности жидкой фазы и ретроградации усвояемого $\mathrm{P}_{2} \mathrm{O}_{5}$. Более легкое разложение желваковых фосфоритов в сравнении с оболовыми наблюдалось также при гидротермическом процессе их обесфторивания.

Таким образом, проведена систематизация природных фосфатов с точки зрения их состава, физико-химических и технологических свойств. В этой системе важнейшим показателем, от которого зависит ряд других свойств, является степень замещения фосфатиона карбонатионом в фосфатном минерале фосфата. На основе проведенной работы сделаны практические предложения по более рациональному использованию фосфатного фонда СССР, например, о предпочтительном использовании оболовых фосфоритов для процессов химической переработки, а желваковых фосфоритов, в пределах надобности, - для производства фосфоритной муки.

\section{Л И Т Е Р А Т У Р А}

1. Вейде рм а М., В еским я э Х., Тр. научно-техн. конференцин «Оболовые фосфо. риты как сырье для химической промышленности». Таллин, 1968, с. 19.

2. В ейде р м а М., В ески м я э Х., Изв. АН ЭССР. Хим. Геол., 20, № 1, 8 (1971).

3. В ейде р м а М., К н уб о в ец Р., Изв. АН ЭССР. Хим. Геол., 21, № 1, 57 (1972).

4. А н со Я. Я., В ейд е м а М. А., К а се са л у С. П., Хим. пром., № 7, 537 (1962).

5. В ейд е р м а М. А., Тр. Таллинск. политехн. ин-та, сер. А, № 210, 305 (1964).

Талинский политехнический институт

Поступила в редакцию 11/VII 1975

\section{VEIDERMA}

\section{LOODUSLIKE FOSFAATIDE VORDLEV FUUSIKALIS-KEEMILINE JA TEHNOLOOGILINE ISELOOMUSTUS}

Uuriti NSV Liidu erinevate leiukohtade fosforiite ning määrati nende keemilis-mineraloogiline koostis, struktuur, reaktsioonivőime ja muud näitajad. Selgus, et fosforiite saab hästi süstematiseerida nende apatiitmineraali fosfaatiooni karbonaatiooniga asendumise astme järgi.

\section{VEIDERMA}

\section{COMPARATIVE PHYSICO-CHEMICAL AND TECHNOLOGICAL CHARACTERISTICS OF PHOSPHATE ROCK}

A systematics of natural phosphates from various deposits of the USSR was developed from the point of view of their composition and physico-chemical and technological properties. The most significant indicator in that system, in which a number of other properties are involved, is the degree of substitution of the phosphate ion by the carbonate ion in the apatite mineral of natural phosphates. 